\title{
The Diffusion
} of Policy Innovations

An Experimental Investigation

Jean-Robert Tyran and Rupert Sausgruber

May 2003 Discussion Paper no. 2003-14 


$\begin{array}{ll}\text { Editor: } & \text { Prof. Jörg Baumberger } \\ & \text { University of St. Gallen } \\ & \text { Department of Economics } \\ & \text { Bodanstr. } 1 \\ & \text { CH-9000 St. Gallen } \\ & \text { Phone } \quad+1712242241 \\ & \text { Fax } \quad+41712242885 \\ & \text { Email joerg.baumberger@ unisg.ch } \\ & \text { Forschungsgemeinschaft für N ationalökonomie } \\ & \text { an der Universität St. Gallen } \\ & \text { Dufourstrasse 48 } \\ \text { Publisher: } & \text { CH-9000 St. Gallen } \\ & \text { Phone } \quad+41712242300 \\ & \text { Fax } \quad+41712242646 \\ & \text { Www.fgn.unisg.ch/public/public.htm }\end{array}$




\title{
The Diffusion of Policy Innovations
}

\author{
An Experimental Investigation
}

Jean-Robert Tyran

and

Rupert Sausgruber ${ }^{1}$

Authors' addresses:

\author{
Dr. Jean-Robert Tyran \\ Department of Economics \\ Bodanstr. 1 \\ $\mathrm{CH}-9000 \mathrm{St}$. Gallen \\ Tel. $\quad$ +41712315 \\ Fax $\quad+41712816$ \\ Email_Lean-Robert.Tyran@ unisg.ch \\ W ebsite http://www.vwa.unisg.ch/tyran/ \\ Dr. Rupert Sausgruber \\ Department of Public Economics \\ University of Innsbruck \\ Universitätsstr. 15 \\ A-6020 Innsbruck \\ Email_Rupert.Sausgruber@ uibk.ac.at \\ W ebsite http://homepage.uibk.ac.at/homepage/c404/c40422/
}

\footnotetext{
${ }^{1}$ W e gratefully acknowledge financial support by the Austrian $\mathrm{N}$ ational Bank, Jubiläumsfonds under project no. 9134. W e are grateful for comments by Ernst Fehr, Simon Gächter, Simon Hug, Arno Riedl, Frans van W inden and seminar participants at the U niversities of A msterdam, Erfurt, and St. Gallen.
} 


\begin{abstract}
W hat causes a government to adopt a new program or policy? Despite a large number of empirical studies available to date, the relative importance of various determinants remains obscure because of difficulties of statistical identification. W e present an experimental setting to study the diffusion of policy innovations in the laboratory. 0 ur approach discriminates between experimentation, experience, and emulation as determinants of policy adoption. The policy innovation we study is an internalization tax to mitigate a local market externality. 0 ur results demonstrate the importance of information about innovations in other states in the diffusion of policy innovations.
\end{abstract}

\title{
Keywords
}

Policy emulation, policy experimentation, innovation.

\section{JEL Classification}

C9, D7, H7. 


\section{Introduction}

What causes a government to adopt a new program or policy? Ever since the seminal studies by Walker (1969) and Gray (1973), the study of state policy innovation has been a major topic in political science (see Savage 1985, Berry 1994 for surveys). Today, the spread of a policy innovation is usually explained by referring to two groups of determinants (Berry and Berry 1990). According to the first group called "internal determinants", social, economic, political and other characteristics of a state determine a state's innovativeness. According to "regional diffusion", the probability of a state adopting a particular policy is higher if neighboring states have already adopted the policy. While the early literature has analyzed the two groups of determinants separately, the current practice is to analyze the two groups jointly, using event history analysis (EHA).

This practice has recently met with growing criticism on three grounds. First, it is criticized on purely statistical-analytical grounds. If, for example, neighboring states are similar in some unobserved dimension, and if this dimension affects the decision to adopt a policy, regional patterns of policy adoption may be misinterpreted as regional diffusion. Limitations of the EHA approach have been pointed out, raising doubts about the validity of conclusions drawn from EHA. In particular, discriminating internal determinants from diffusion seems to be more critical on statistical grounds than previously thought (Frant 1991, Mooney 2001, Myers 2001).

Second, it is criticized that much of the literature has been more concerned with showing whether policy diffusion exists at all, and less with the factors determining policy diffusion. In contrast to the mere spread of a policy, genuine policy diffusion involves policy emulation which according to some authors necessarily involves communication between states. For example, Rogers (1995: 5) notes: "Diffusion is the process by which an innovation is communicated through certain channels over time among the members of a social system". Several researchers have indeed provided investigations into the role of information flows in policy diffusion (Canon and Baum 1981, Mintrom and Vegari 1998). Studies on the role of political leaders and state officials (Caldeira 1985, Grupp and Richards 1975, Menzel and Feller 1977) suggest that "laggards" take cues from early adopters.

Third, it seems to be almost impossible to disentangle different mechanisms in the diffusion of policy innovations. While it is quite plausible that political decision makers 
emulate policies and take cues from other states, alternative explanations seem equally plausible. For example, political economists have argued that policy innovations are adopted because of interstate competition for mobile production factors or because of other spillover effects (Besley 2000, Feld 1997, Heyndels and Vuchelen 1998, Karch 2001, Ladd 1992). In addition, it has been noted that the spread of policy innovations may not only be affected by horizontal factors (operating from state to state), but may also be determined by vertical factors, involving federal government (Smith 2001, Welch and Thompson 1980). Finally, the empirical study of policy diffusion is difficult because early adopters may later renounce the policy (Eyestone 1977), and the substance of a policy innovation may be massively altered in spreading from state to state (Glick and Hays 1991). In view of these criticisms, the evidence on the existence and the determinants of policy diffusion looks weak and inconclusive (Mooney 2001, Myers 2001, Smith 2001).

This paper suggests an experimental approach to policy diffusion to shed new light on the role of information in the adoption of policy innovations. We present an experimental setting with several "laboratory states". Each state consists of an independent economy and polity. That is, citizens of each state have the discretionary political power to adopt a policy innovation. Citizens earn incomes in a market, but the market generates a local externality. Citizens vote in a referendum on the adoption of an internalization tax to mitigate the externality and to improve market efficiency. We study the adoption of a tax policy innovation over a series of referenda in two conditions which exclusively differ with respect to whether citizens are informed about innovation decisions and innovation outcomes in other states.

Our experimental approach has several advantages over field studies. First, by holding all potential internal determinants constant across states we discriminate internal determinants from regional diffusion. Second, we are able to unambiguously isolate the role of information in the process of policy diffusion. In particular, we discriminate between policy experimentation, experience, and policy emulation as factors contributing to the spread of the tax policy innovation. Third, we hold the substance of the policy constant over time, and by making state economies fully independent we discriminate the effect of information from other factors potentially promoting diffusion, like inter-jurisdictional competition and spillovers.

Our approach to policy diffusion is novel, and has important advantages over other modes of empirical investigation. In particular, we unambiguously identify the role of 
information flows in policy innovation by applying experimental techniques (on the use of experimental methods in political science see Kinder and Palfrey 1992, Lupia and McCubbins 1998, McDermott 2002). While our experimental study is explorative in nature, we believe that the experimental approach to policy innovation usefully complements field studies like EHA and simulation studies (e.g., Kollmann et al. 1997, 2000).

We proceed as follows. Section 2 describes the experimental design, and explains the advantages of an experimental approach to the diffusion policy innovation. Section 3 reports the results, and section 4 concludes.

\section{Experimental design}

Section 2.1 provides a broad description of the experiment, section 2.2 explains the parameters and predictions for the market, and section 2.3 provides detailed information about the political decision to be taken in the referendum.

\subsection{General description}

The basic unit of analysis in our experiment is a "state". In each state, there is a number $m$ of participants (henceforth "citizens"). Citizens are immobile, in the sense that they remain in the same state throughout the experiment. All citizens are voters who decide on the adoption of a policy innovation by majority vote. The economy in each state consists of a market, and citizens earn incomes by trading on the market. However, trading causes an externality. That is, each unit traded in the market reduces incomes for the other $m-1$ citizens in the state. If citizens do not take this externality into account, market activity is predicted to be inefficiently high. State economies are independent in the sense that trading in one market does not (directly) affect outcomes in other markets. In particular, there are no spillovers between markets and, therefore, externalities are purely local. In each state, a referendum on the adoption of a policy innovation ${ }^{1}$ is held. The policy innovation is a tax on externalitygenerating market transactions. Hence, the policy innovation is efficiency-enhancing in equilibrium, and a majority of citizens benefits from the policy innovation in equilibrium.

\footnotetext{
1 According to Walker (1969: 881) a policy innovation is a "policy which is new to the states adopting it, no matter how old the program may be or how many other states may have adopted it."
} 
There are two treatments which exclusively differ with respect to the availability of information about adoption decisions and about policy outcomes in other states. In T(full), full information about adoption decisions in all states is available, while in $\mathrm{T}$ (no) no such information is available. Hence, policy emulation is possible in $T$ (full) but not in $T$ (no). According to Rogers (1995: 18) emulation is key to diffusion. He notes that "the heart of the diffusion process consists of the modeling and imitation by potential adopters of their network partners who have adopted previously". In T(full), each participant is informed about whether the policy innovation was adopted and about average income in each state (see arrows in figure 1).

Figure 1: $\quad$ Illustration of treatment conditions

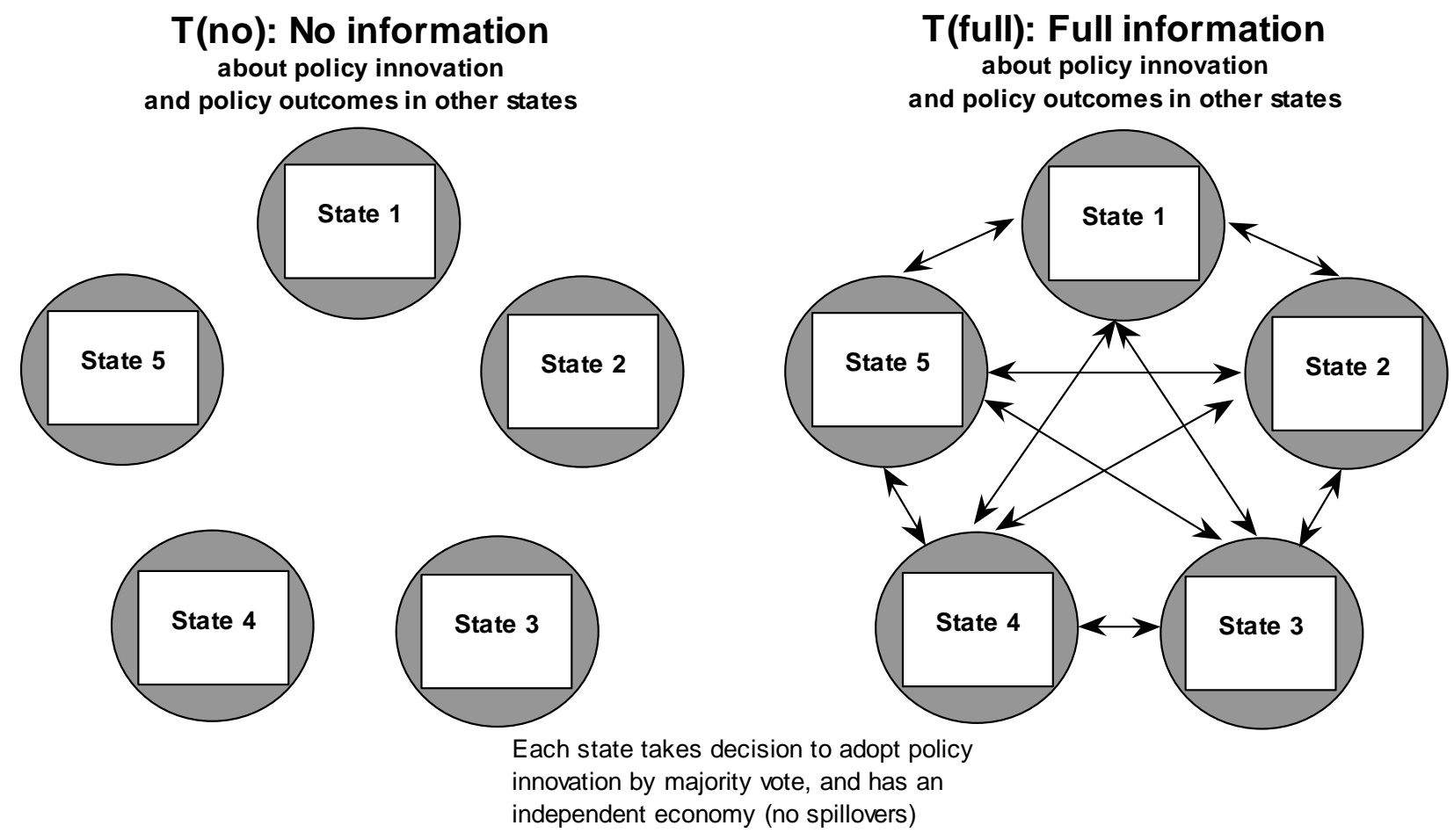

Participants have private information about market parameters. That is, participants only know their own market valuations for the traded good. This implies that participants cannot predict the market consequences of adopting the policy innovation in equilibrium. While voters cannot ex ante determine whether the policy innovation is to their benefit, they may learn over time whether it is in their material self-interest to implement the policy innovation. We have chosen a sequence of voting and trading that allows for learning along three dimensions (see below for explanations). Figure 2 shows that, after an initial phase 0, there are three main phases. Each main phase starts with a referendum on the implementation of the 
policy innovation. If the policy innovation is accepted by a majority of voters, the tax is levied for the consecutive 15 market periods. If the innovation is rejected, no tax is levied for the consecutive 15 market periods.

Figure 2: $\quad$ Sequencing of phases

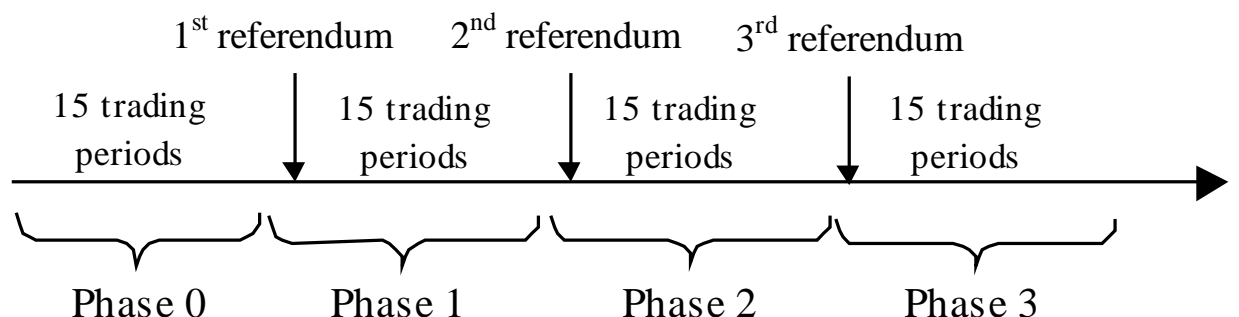

It is important to note that we hold internal determinants constant across states. In our experiment, all 5 states are identical, and voters have the same (induced) preferences in all 5 markets. By virtue of our experimental design, we can exclude several alternative explanations for the diffusion of policies. In particular, there are no spillovers between states. Note also that the link between the markets/states of each country is purely informational, and does not, for example, involve aspects of inter-jurisdictional competition or other strategic aspects. Holding the properties of the policy innovation constant throughout the experiment facilitates learning. In contrast, it often takes several decades for policy innovations to spread across states in the field which may create important structural breaks affecting the "attractiveness" to adopt a policy innovation.

From the perspective of participants, experimentation is risky, as explained above. However, policy emulation, in the sense of imitating a state which has successfully adopted a policy innovation is risky, too. The reason is that subjects do not know that other markets have exactly the same cost and value structure as their own market. However, they do know that the situation is similar in other states. In particular, they know that an externality problem prevails and that the decision is about the adoption of a tax policy innovation in other states, too. Hence, given this imperfect information, subjects have to learn about the relevance of the information revealed in other markets for their own market. Finally, subjects not only have limited information about the market parameters in their market and about the prevailing conditions in other markets, they also lack perfect information on the temporal structure of the experiment. In particular, they do not know how many main phases consisting of a referendum and 15 market periods are implemented. This limited information attenuates 
possible free-riding incentives as postulated by Kotsogiannis and Schwager (2001) and Strumpf (2002). Not knowing how many opportunities there are to learn from others' decisions reduces the incentives for voters in one state to adopt a "wait-and-see" policy, thereby increasing incentives for policy experimentation.

We use an internalization tax as an example of a policy innovation. We can, by virtue of experimental techniques, predict and observe whether this innovation is efficiency-increasing, and who stands to gain from its implementation. This ability to control constitutes an important advantage over research with field studies where efficiency and distributional properties of particular policies are largely unknown. As a consequence, field studies can, in general, not determine whether a particular policy should be adopted on efficiency grounds.

\subsection{Parameters and predictions for the experimental markets}

The market we implement is a computerized two-sided auction with $m=5$ human buyers and automated sellers (see instructions in appendix A). In all our experimental markets we use the parameters shown in figure 3. The figure depicts the induced demand $(D)$, the private cost function $C_{p r}$, and the social cost function $C_{s o c}$. Each buyer can at most buy one unit. In each market there is one high-valuation buyer with a value of $v_{i}=140$, and four lowvaluation buyers with $v_{i}=60$. Buyers earn income by trading. A buyer's income is higher if he buys at a lower price. In particular, buyer $i$ 's gross income is his value minus the market price $\left(\pi_{i}=v_{i}-p\right)$.

Trading causes external effects. In particular, a marginal external cost of $C_{\text {ext }}=90$ adds to the private cost of $C_{p r}=10$, and results in constant social cost of $C_{s o c}=100$. All $m=5$ market participants are equally affected by the externality. Hence, the per-capita external cost per unit traded is $C_{\text {ext }} / m=18$ points.

In the absence of taxation, the supply is horizontal at $C_{p r}=10$. In competitive equilibrium five units are traded $\left(q^{*}=5\right)$ at a price of $p^{*}=10$ (see figure 3 ). Note that the equilibrium quantity $q^{*}=5$ is the only Nash equilibrium outcome. To see this, note that buyer $i$ 's transaction causes total external costs of $C_{\text {ext }}$. Of this, a fraction $C_{\text {ext }} / m$ falls back on $i$. By submitting bids smaller than the difference of their value and the per-capita external cost $\left[v_{i}-\left(C_{e x t} / 5\right)\right]$, buyers gain from trade. This implies that it is a best reply for each buyer to buy at the equilibrium price at $p^{*}$. Since the automated sellers are programmed to ask their true cost, and to accept and bid above private costs, buyers always have an incentive to trade. 
Figure 3: Market parameters

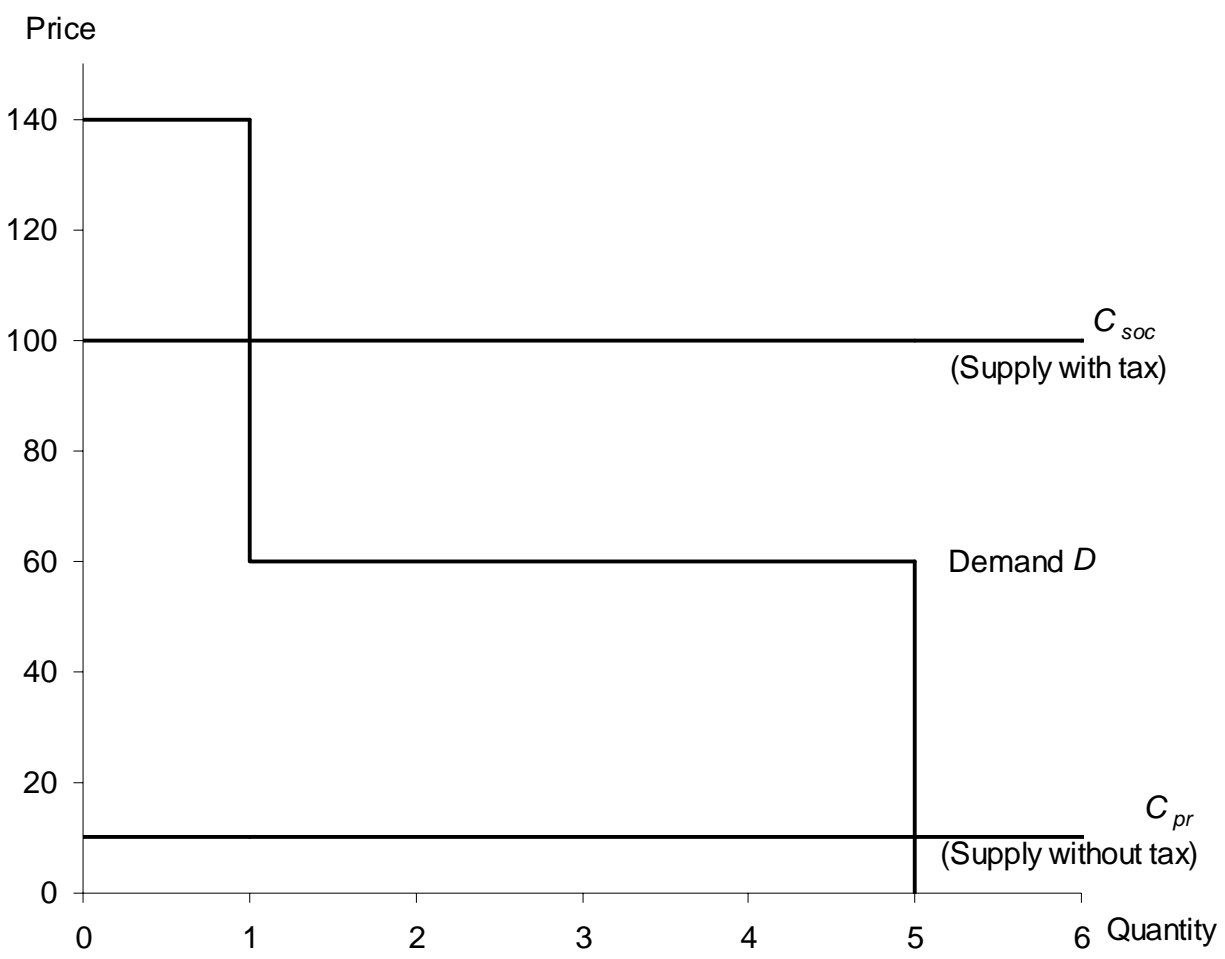

In equilibrium, the distribution of rents is uneven. The high-valuation buyer's net income per period is 40 points (= a value of 140 minus the equilibrium price of 10 minus the per-capita external cost for $q^{*}=5$ units). In contrast, each of the four low-valuation buyers faces a gross loss of 40 points in equilibrium. For practical purposes, we want to avoid that subjects incur losses from trading. To exclude losses, low-valuation buyers receive a flat fee of 50 points per period. Since this fee is paid independent of behavior, it does not affect optimal choices.

In the absence of the policy innovation, the market outcome in equilibrium is highly inefficient. Efficiency is measured as the sum of total market rents. In competitive equilibrium, the social cost of production is $500\left(=q^{*} \times C_{s o c}\right)$, and the sum of private reservation values is $380(=140+4 \times 60)$ points. Hence, efficiency in the absence of the policy innovation is -120 .

If the policy innovation is implemented, a tax of 90 points is levied on each unit traded. This shifts the supply curve to the level of social cost and reduces equilibrium quantity to one unit, $q_{\operatorname{tax}} *=1$. As a consequence, the equilibrium price increases by the full amount of the tax to a price of $p_{t a x} *=100$ (see figure 3 ). In equilibrium, the policy innovation is efficiencyenhancing in the sense that it increases the sum of rents. The gross income of the high- 
valuation buyer is 22 (= 140 - price of 100 - per-capita externality of 18$)$. The gross income of each low-valuation buyer is -18 (= per-capita externality of -18). Hence, the sum of rents with the policy innovation is $-50(=22-4 \times 18)$. Therefore, the policy innovation induces a considerable efficiency increase (from -120 to -50 ).

Note that low-valuation buyers gain from the policy innovation. Because of the reduction in external cost, equilibrium gross payoff increases from -40 to -18 points. In contrast, the high-valuation buyer loses from the policy innovation. His equilibrium payoff falls from 40 to 22 points. The distributional effects of the policy innovation imply that only low-valuation buyers have an incentive to vote for the policy innovation. The reason why the policy innovation does not result in a Pareto-improvement (making everybody better off) is that we do not redistribute tax revenues to keep the experiment cognitively simple.

The market mechanism we use is a uniform-price sealed bid/offer auction (see Smith et al. 1982 for a detailed description). In this auction, human buyers can submit integer numbered bids not exceeding redemption values. The automated sellers are programmed to offer their units equal to the true unit costs assigned. Computerization of the sellers' market side makes the allocation procedure in the market strikingly simple. In the market without tax, any bid greater or equal to 10 is accepted. In the market with the tax, only the high-valuation buyer can submit an acceptable bid above or equal to 100. The market quantity is the number of accepted bids, and the uniform market price is set equal to the lowest accepted bid.

\subsection{Policy innovation and policy emulation}

At the beginning of the experiment, subjects are handed out detailed instructions on the proposed policy innovation (see appendix B). At the beginning of each main phase, a referendum is held (see figure 2). All participants (i.e., the buyers) vote, the automated sellers do not vote. In the referendum, each buyer in the market votes either Yes or No, abstentions are not possible. The policy innovation is adopted if a majority of voters approves.

At the beginning of each main phase, subjects are given 10 minutes to take their voting decision. During this time they review information on the past phase. The computer shows information on past market prices, quantities, the per-capita externalities, accumulated and per-period earnings and the average per-capita income within the market. In addition, in $\mathrm{T}$ (full) subjects are provided with information about which of the other markets have accepted 
or rejected the policy innovation and about the resulting average per-capita income in each of the other four markets.

Differences in the rate of policy innovation over time can in principle be explained by three factors in our setting: experimentation, experience, and policy emulation. By experimentation we mean that voters in states which have not yet adopted the policy give it a try. By experience we mean that those who adopted the policy innovation take their decision in the next referendum according to the experience they made with the innovation. By policy emulation we mean that states who have not adopted the policy innovation so far, but were able to observe other states who have, adopt the policy if they see that it is more successful than non-adoption.

The design lends itself to isolate the effects of experimentation, experience, and policy emulation. In phase 0, policy innovation is not possible by design, and this phase serves as a benchmark to measure the efficiency-increasing effects of policy innovation. Phase 1 serves to measure the effect of experimentation in both treatments. Since subjects do not have sufficient information to actually calculate the effect of the policy innovation on market incomes, they must give it a try if they want to find out. However, note that it is in the material self-interest of the low-valuation buyers to vote for the policy innovation, but it is in the material self-interest of the high-valuation buyers to vote against the policy innovation.

Phase 2 serves to isolate the effect of policy emulation by comparing outcomes across phases and treatments. States who have not adopted the policy in phase 1 of T(no) but who do adopt in phase 2 do so because of experimentation. In T(full), those who have not adopted the innovation in phase 1 but who do adopt in phase 2 do so because of either experimentation or emulation. Given that experimentation is equally common in the two treatments, an across treatment comparison isolates the effect of emulation.

The effects of experimentation, experience, and emulation can be measured in terms of referendum and market outcomes (see sections 3.1 and 3.2) or in terms of voting decisions (see section 3.3) in our design. This distinction is important because a particular determinant may, for example, strongly affect individual voting but because of majority requirements only weakly affect referendum and subsequent market outcomes. 


\section{Results}

In total, 115 students from the faculties of science, arts, and theology participated in our experiment at the University of Innsbruck, Austria. Subjects on average earned about $€ 15$ (including a show-up fee of $€ 4$ ) within approximately 80 minutes. The experiments were programmed using the software zTree (Fischbacher 1998).

The main results are that market outcomes reliably converged to theoretical predictions (section 3.1.), that policy emulation induced about a quarter of the states to adopt the policy innovation and caused corresponding efficiency gains (section 3.2.). In section 3.3., we take a closer look at individual voting behavior to account for observed referendum and market outcomes.

\subsection{Market outcomes}

We find that the experimental markets under study have a strong tendency to produce equilibrium outcomes. Markets in which the policy innovation is not implemented have average prices that quickly converge from above to the prediction of $p^{*}=10$ (see figure 4). For example, without tax the average price over all periods in phase 0 is 18.5 , in phase 3 it is 10.8. This observation is in line with investigations of similar experimental markets with externalities (e.g., Plott 1983, Harrison et al. 1987). Quantities are also relatively close to the prediction of $q^{*}=5$, and as a consequence, efficiency is low. In phase 0 , when the policy innovation is not feasible by design, average traded quantity is 4.7 , and efficiency is at -111.8 , which is already quite close to the prediction of -120.0 . In phase 3 , markets without tax converge even closer to the predictions. For example, the average quantity traded in markets without tax in phase 3 is 4.9 , and average efficiency is -116.4 .

In markets with the policy innovation, average transaction prices do converge to the theoretical equilibrium of $p_{t a x} *=100$, but convergence is somewhat slower than in markets without the tax. The average transaction price in phase 1 is 109.6 , in phase 3 it is 103.5. Average efficiency is -44.2 in phase 1 , and -39.4 in phase 3 . Hence, deviations from equilibrium are somewhat larger than in the case without tax. The reason is that when a tax is levied on transactions, only one active buyer (the high-valuation buyer) remains in the market. Obviously, a market with one buyer is less effective than a market with five active buyers in bringing about equilibrium outcomes. However, note that efficiency is clearly higher with 
than without the policy innovation. Over all phases, efficiency is by 71.2 units higher with than without the policy innovation. This is very close to the predicted change in efficiency of 70.0 units.

Figure 4: Average transaction prices

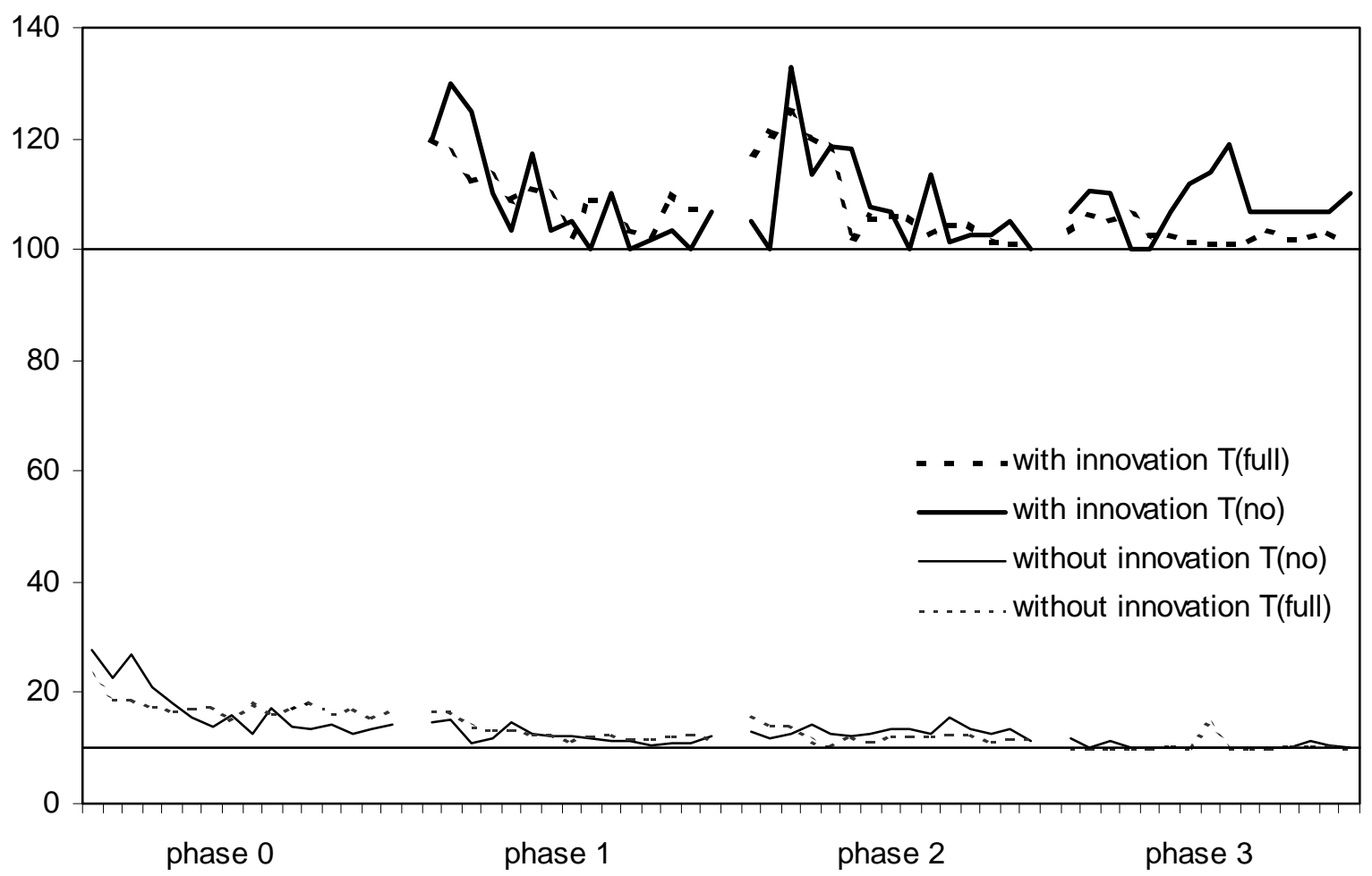

The distributional effects of the policy innovation are close to theoretical predictions, too. Importantly, every single low-valuation buyer in fact gains and every high-valuation buyer loses from the policy innovation in comparison with the situation without tax. Therefore, a majority of voters (i.e., 80 percent) gain from the policy innovation. We summarize the preceding discussion as follows.

Result R1: $\quad$ Experimental markets reliably equilibrate irrespective of whether the policy innovation is adopted or not. As a consequence, the policy innovation is efficiency-enhancing and increases incomes for a majority of voters.

Result R1 sets the stage for our analysis below. Only if the policy innovation indeed is efficiency-enhancing can we expect more widespread adoption to translate into efficiency gains. Moreover, only if a majority of voters actually gains from the innovation should we expect policy diffusion among rational and self-interested agents. As has been shown above, both of these preconditions are met in our study. 


\subsection{Information and policy diffusion}

Differences in the rate of policy innovation over time can in principle be explained by the three factors in our setting: experimentation, experience, and policy emulation. The effect of these factors on referendum and market outcomes can be assessed by comparing the two treatments in the four phases. A more detailed analysis of voting behavior is provided in section 3.3.

In phase 0 , policy innovation is not possible in either treatment by design. Since the two treatments are structurally identical in this phase, we expect no behavioral difference across treatments in phase 0. In fact, the average number of units traded [4.8 in T(no), 4.8 in $\mathrm{T}$ (full), $p=0.767$, average market prices [16.4 in T(no), 17.3 in T(full), $p=0.518]$, and efficiency [112.7 in $\mathrm{T}(\mathrm{no}),-111.8$ in $\mathrm{T}(\mathrm{full}), p=0.768$ ] are statistically indistinguishable across treatments according to Mann-Whitney tests.

In phase 1, policy innovation is possible in both treatments. Since the first referendum is the first opportunity to accept the policy innovation, participants had no opportunity to learn from their own experience, and policy emulation is not yet possible in T(full). As a consequence, differences in the rate of policy innovation can exclusively be attributed to differences in subjects' propensity to experiment. The rate of policy innovation is slightly higher in treatment $\mathrm{T}($ no) than in $\mathrm{T}$ (full). In particular, in $\mathrm{T}($ no) 38 percent $(=3 / 8)$ of states adopt the innovation while in $\mathrm{T}$ (full) the adoption rate is only 27 percent $(=4 / 15)$. These differences in adoption rates translate into differences in market outcomes. Figure 5 shows normalized efficiency in the two treatments over all phases. Efficiency is normalized such that equilibrium efficiency without the policy innovation is set equal to 0 , and equilibrium efficiency with the policy innovation is set equal to 100 . As can be seen, average market efficiency is slightly higher in T(no) (40.9 percent) than in T(full) (32.0 percent) in phase 1 . However, efficiency is not significantly different in the two treatments (Mann Whitney, $p=$ 0.455). We conclude that experimentation had no significant effect in the two treatments. 
Figure 5: $\quad$ Average efficiency in percent (normalized)

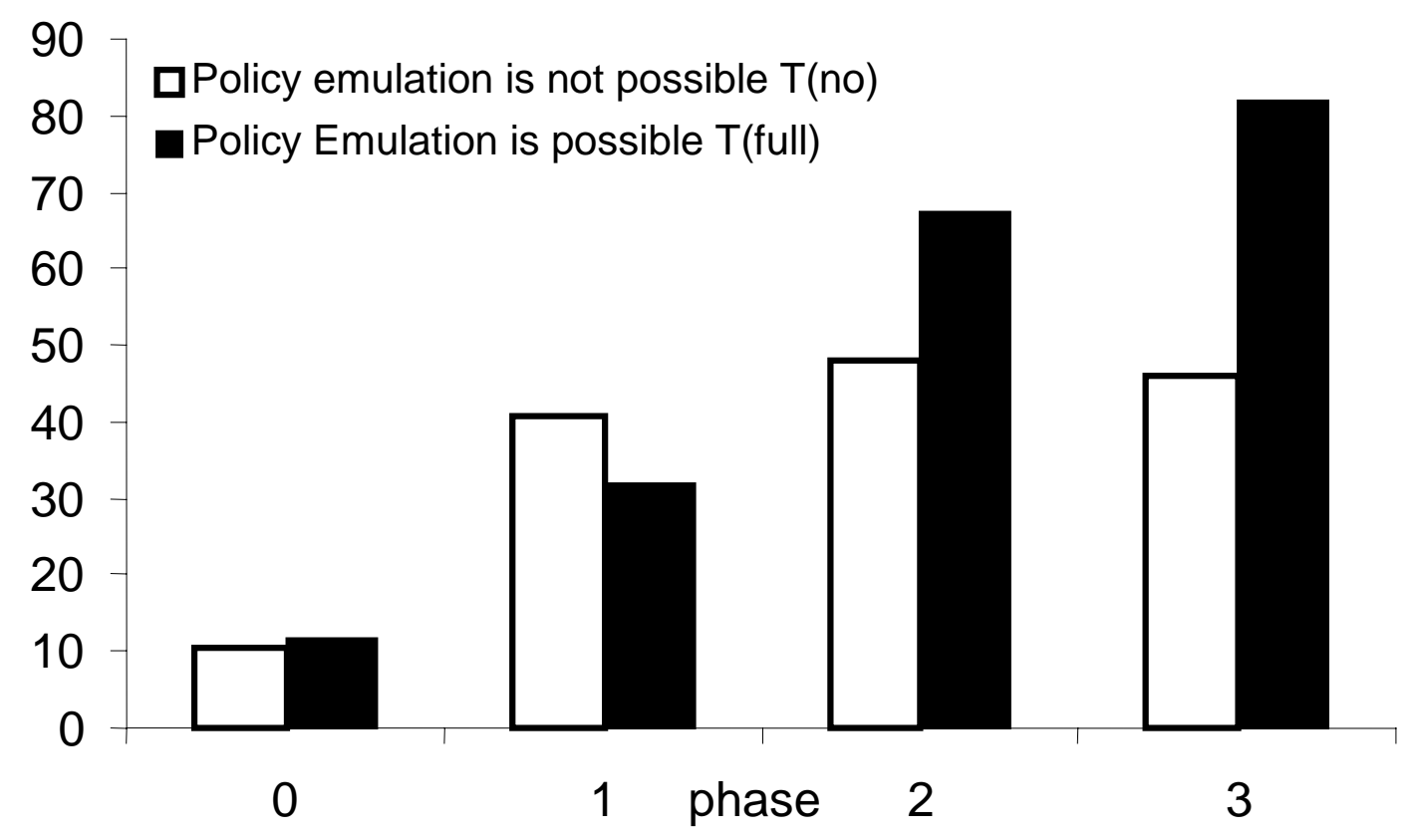

Phase 2 provides the main test for the importance of policy emulation in the diffusion of policy innovation. In T(full) 73 percent $(=11 / 15)$ of states accept the proposal in phase 2 . This is a significant increase in comparison to phase 1 where only 27 percent adopted the policy innovation (McNemar Change test, $p=0.035$ ). In contrast, in $\mathrm{T}(\mathrm{no})$ the percentage of adopting states does not change significantly (the increase from 38 percent in phase 1 to 50 percent in phase 2 is not significant according to a McNemar Change test, $p=0.750$ ). To isolate the causal effect of policy emulation on policy innovation we first calculate the percentage of those who have not yet experienced the effect of innovation, but adopt the policy in phase 2 in $\mathrm{T}$ (full). Out of the 11 states in $\mathrm{T}$ (full) which have not experienced the policy innovation in phase 1,64 percent $(=7 / 11)$ do adopt in phase 2 . In T(no), 5 states have not adopted the policy innovation in phase 1. Of these, 2 states adopt in phase 2. Therefore, the rate of policy innovation due to experimentation is 40 percent $(=2 / 5)$ in $T($ no). Since experimentation was found to have the same effect in both treatments, the difference between these two percentages isolates the effect of emulation on policy innovation. We conclude that emulation caused 24 percent $(=64 \%-40 \%)$ of states to adopt the policy in phase 2 . Because the policy is efficiency-increasing, the differences in the rate of policy innovation translate into corresponding differences in efficiency in the two treatments. In particular, normalized efficiency increases from 32.0 in phase 1 to 67.5 in phase 2 in $\mathrm{T}$ (full) while the corresponding 
increase is only from 40.8 to 48.1 in $\mathrm{T}$ (no). Therefore, the efficiency increase of 28.2 points [(67.5-32.9) - (48.1-40.8)] from phase 1 to phase 2 is caused by policy emulation.

Phase 3 analogously isolates the effect of policy emulation by measuring the differential outcomes in phase 2 and phase 3 across treatments. Since more markets have adopted the policy, and some states have repeatedly adopted the policy, the states which have not yet adopted the policy can now base their emulation decision on a broader informational (statistical) base. While this leads us to expect a higher rate of emulation in phase 3 , the number of potential variations necessarily shrinks in phase 3, making statistical inference less powerful. We find that of those states which have not adopted the policy in $\mathrm{T}($ full) in phase 2, again 50 percent $(=2 / 4)$ do adopt in phase 3 . In $\mathrm{T}(\mathrm{no})$, the corresponding figure is 25 percent $(=1 / 4)$. We conclude that emulation caused 25 percent $(=50 \%-25 \%)$ of the states to emulate the policy innovation in phase 3 . As can be seen from figure 5, normalized efficiency increases in $\mathrm{T}$ (full) from 67.5 percent in phase 2 to 81.8 percent in phase 3 . In contrast, normalized efficiency slightly falls in T(no) (from 48.1 in phase 2 to 46.2 in phase 3 , see figure 5). In all, the option to emulate policy innovations in $\mathrm{T}($ full) leads to a significantly higher efficiency in $\mathrm{T}$ (full) than in $\mathrm{T}(\mathrm{no})$ in phase 3 according to a Mann Whitney test $(p=$ $0.028)$.

Result R2: Policy emulation causes higher rates of policy innovation (of about 25 percent of the states), and induces a corresponding efficiency gain in adopting states.

\subsection{Analysis of individual voting behavior}

We now assess the relative importance of experimentation, experience, and emulation for individual voting decisions. This analysis serves to detect whether the importance of determinants is affected by aggregation. In the following, we restrict our analysis of individual voting behavior to low-valuation buyers. ${ }^{2}$ The reason is that these buyers are predicted to gain from the policy innovation and, therefore, these voters have a material incentive to approve of the policy innovation.

\section{A) Experimentation}

In the $1^{\text {st }}$ referendum, votes for the innovation can be attributed to experimentation in both treatments. In T(full) 35 percent $(=21 / 60)$, and in $\mathrm{T}($ no) 47 percent $(=15 / 32)$ vote for the innovation. We do not find strong support for the free-riding hypothesis (e.g., Strumpf 2002)

\footnotetext{
${ }^{2}$ This is for the ease of exposition. High-valuation buyers' decisions are qualitatively similar.
} 
since the rate of experimentation is not significantly lower in $\mathrm{T}$ (full) than in $\mathrm{T}$ (no) in phase 1 ( $p=0.787$, Chi-square test). However, this may be due to subjects' limited information about the temporal structure of the experiment. Experimentation can be isolated by those who were in non-innovating states in previous phases but who adopt the innovation in the current phase in $\mathrm{T}\left(\right.$ no). Accordingly, 45 percent $(=9 / 20)$ approve because of experimentation in the $2^{\text {nd }}$ referendum and 56 percent $(=9 / 16)$ do so in the $3^{\text {rd }}$ referendum. We conclude that the overall rate of experimentation is mostly below but close to what would have resulted from random voting decisions (i.e., 50\%), and relatively stable over phases. Note that because these percentages constitute a minority of votes in many cases, experimentation induces relatively little adoption of the policy innovation.

\section{B) Experience}

The effect of experience on voting behavior is measured by the percentage of those who approve in the current phase upon having adopted the policy innovation in the previous phase. In phase 2 of $\mathrm{T}(\mathrm{no})$, the effect of experience is 67 percent $(=8 / 12)$ and in phase 3 the corresponding figure is 63 percent $(=10 / 16)$. In $\mathrm{T}$ (full), the corresponding figure for phase 2 is 50 percent $(=8 / 16)$, and 67 percent $(=24 / 36)$ for phase 3 . Hence, up to two thirds of those who experienced the beneficial effects of the policy innovation vote in order to uphold the innovation in later periods. Since experience on average induces a majority to vote for the policy innovation, this implies that the innovation is usually upheld once it is adopted. In fact, 71 percent $(=12 / 17)$ of the markets that adopt the policy in the $1^{\text {st }}$ or $2^{\text {nd }}$ referendum uphold the innovation in all following referenda.

\section{C) Emulation}

In principle, the effect of emulation on individual voting behavior can be measured in two ways. The first consists in calculating the percentage of those approving among those who have no previous experience in $\mathrm{T}(\mathrm{full})$, and subtracting the percentage of Yes votes among those without experience in $\mathrm{T}(\mathrm{no})$ in a given referendum. This, of course, assumes that the willingness to experiment is the same in the two treatments (as is approximately the case, see A) above). This measure yields an effect of emulation of 12 percent in the $2^{\text {nd }}$ referendum, and of 19 percent in $3^{\text {rd }}$ referendum. Comparing these effects of emulation on individual voting with the effects of emulation on the actual rate of policy adoption shows that the latter effect was slightly stronger ( 25 percent). Therefore, aggregation induced a slight bias in favor of policy adoption. This is not too surprising since subjects voted for policy innovation in $\mathrm{T}(\mathrm{no})$ at rates of or below 50 percent, but at rates of about 60 percent in $\mathrm{T}$ (full). 
A second way to assess the effect of emulation on individual voting behavior is to test whether the incidence of "learning" (i.e., switching from No to Yes) is significantly higher when emulation is possible than when it is not possible. Table 1 shows the voting decisions of inexperienced low-valuation buyers, i.e., the voting decisions of those who have not adopted the innovation previously. The first number in each cell refers to T(full), the second number to $\mathrm{T}\left(\right.$ no). For example, the number of inexperienced voters who voted Yes in both the $1^{\text {st }}$ and the $2^{\text {nd }}$ referendum was 9 in $\mathrm{T}($ full) and 5 in $\mathrm{T}($ no) (see upper left cell of table 1).

Table 1: Voting decisions of inexperienced low-valuation buyers in treatment $\mathrm{T}$ (full) / T(no)

\begin{tabular}{|c|c|c|c|c|c|}
\cline { 3 - 6 } \multicolumn{2}{c|}{} & \multicolumn{2}{c|}{$2^{\text {nd }}$ referendum } & \multicolumn{2}{c|}{$3^{\text {rd }}$ referendum } \\
\cline { 3 - 6 } \multicolumn{2}{c|}{} & \# Yes & \# No & \# Yes & $\#$ No \\
\hline \multirow{2}{*}{$1^{\text {st }}$ referendum } & \# Yes & $9 / 5$ & $2 / 3$ & $3 / 2$ & $0 / 2$ \\
\cline { 2 - 6 } & \# No & $19 / 4$ & $14 / 8$ & $5 / 4$ & $4 / 4$ \\
\hline
\end{tabular}

The left part of table 1 shows that there were 44 inexperienced subjects in the $2^{\text {nd }}$ referendum in T(full). In this treatment, 19 subjects changed voting behavior from No to Yes while only 2 voters changed from Yes to No. This difference is highly significant $(p=0.000$, McNemar change test). In contrast, from a total of 20 inexperienced subjects in T(no) only 4 changed correctly from No to Yes, and 3 changed from Yes to No. Hence, there is no significant learning effect in condition $\mathrm{T}(\mathrm{no})(p=1.000)$. In the $3^{\text {rd }}$ referendum the number of inexperienced subjects decreases in both treatments and limits the power of statistical testing. Yet, a comparison between the $1^{\text {st }}$ and $3^{\text {rd }}$ referendum yields $p$-values for McNemar change tests of $p=0.063$ in $\mathrm{T}$ (full), but of only $p=0.688$ in $\mathrm{T}(\mathrm{no})$. We conclude that policy emulation induced voters to vote for the innovation.

Result R3: Experimentation generally explains less than 50 percent of votes for policy innovation, inducing relatively little innovation in majority voting. Experience induces about two thirds of voters to approve of the innovation, causing adopting states to mostly uphold the innovation. Policy emulation significantly increases the tendency to vote for policy innovation. Emulation induces between 12 and 19 percent of voters to approve. These votes induce disproportionate policy adoption because they add to the votes from experimentation, often yielding majorities. 


\section{Concluding remarks}

This paper has shown that providing political decision-makers with information about policy innovations in other states is a causal factor in the diffusion of an efficiency-enhancing policy innovation. This causal factor is isolated by comparing policy adoption when information about innovation outcomes in other states is available with a situation in which no such information is available. Within this setting, we were able to assess the relative importance of policy experimentation, learning from own experience, and policy emulation.

Our experimental approach is innovative because it combines economic and political decision-making, and our study is the first to analyze the role of information in policy innovation in a laboratory setting. While our study focused carefully on isolating the causal effect of information on policy innovation, we believe that our setting provides a useful starting point to investigate further aspects of the diffusion of policy innovations. We now provide four suggestions for further research.

First, inherent differences in innovativeness between states (so-called "internal determinants") can be investigated in our experimental setting by imposing different structural characteristics on states. For example, the externality could be made more pronounced in some states than in others. Therefore, the tax policy innovation would be more beneficial to some states. We speculate that making states asymmetric reduces the information content of observing innovation outcomes in other states, and that this, in turn, makes policy experimentation more valuable relative to policy emulation.

Second, our setting can be adapted to study the effects of more complex forms of communication between states. Our experiment compared two polar cases: states either obtain no or full information about policy innovations in all other states. Our experiment could be adapted to investigate the effects of intermediate cases with partial and indirect information. For example, information about innovation outcomes could be noisy, or outcomes in one state could only be observed by a subset of states. We expect partial and indirect information to have a less pronounced effect on policy adoption than full information.

Third, our setting can be used to investigate the effect of information on the selection among policy alternatives. In our experiment, there was only one policy innovation to consider, and the policy innovation clearly increased the market incomes of a majority of voters. Our experiment can be adapted to study how information transmission affects the 
selection among a menu of policy innovations. For example, will voters reject efficiencydecreasing policy innovations? Will they be able to discover the most beneficial level of taxation for their state?

Fourth, our setting can be adapted to study how information transmission interacts with inter-jurisdictional competition or spillovers which potentially also promote policy diffusion. In our experiment, citizens were immobile in the sense that they had to remain in the state they were. The experiment could be adopted such that citizens make a locational choice before each referendum on policy innovation. This, for example, provides those who favor the policy innovation but are voted down in their state with an "exit" option. Alternatively, the externality which was purely local in our experiment could be made partly global. For example, external cost in all states could fall as one state adopts the innovation.

These suggestions for further research illustrate that the experimental approach is a promising new line in policy diffusion research. We believe that experimental diffusion research can fruitfully complement other modes of investigation, like field studies and or simulation studies. 


\section{References}

Berry, F.S. (1994): Sizing Up State Policy Innovation Research. Policy Studies Journal 22: 442-56.

Berry, F.S. and Berry, W.D. (1990): State Lottery Adoptions as Policy Innovations: An Event History Analysis. American Political Science Review 84(2): 395-415.

Besley, T. (2000): Political Institutions and Policy Competition. Typescript, London School of Economics.

Besley, T. and Case, A. (1995): Incumbent Behavior: Vote-Seeking, Tax-Setting, and Yardstick Competition. American Economic Review 85(1): 25-45.

Caldeira, G.A. (1985): The Transmission of Legal Precedent: A Study of State Supreme Courts. American Political Science Review 79(1): 178-94.

Case, A.C., Rosen, H.S. and Hines, J.R. (1993): Budget Spillovers and Fiscal Policy Interdependence: Evidence from the States. Journal of Public Economics 52: 285-307.

Eyestone, R. (1977): Confusion, Diffusion and Innovation. American Political Science Review 71(2): 441-7.

Feld, L.P. (1997): Exit, Voice and Income Taxes: The Loyalty of Voters. European Journal of Political Economy 13(3): 455-78.

Fernandez, R. and Rodrik, D. (1991): Resistance to Reform: Status Quo Bias in the Presence of Individual-Specific Uncertainty. American Economic Review 81(5): 1146-55.

Fischbacher, U. (1998): zTree: Zurich Toolbox for Readymade Economics Experiments. mimeo. University of Zurich.

Frant, H. (1991): Specifying a Model of State Policy Innovation. American Political Science Review 85(2): 571-3.

Glick, H.R. and Hays, S.P. (1991): Innovation and Reinvention in State Policymaking: Theory and the Evolution of Living Will Laws. Journal of Politics 53(3): 835-50.

Harrison, G.W., Hoffman, E., Rutström, E.E. and Spitzer, M.L. (1987): Coasian Solutions to the Externality Problem in Experimental Markets. Economic Journal 97(June): 388-402.

Heyndels, B. and Vuchelen, J. (1998): Tax Mimicking among Belgian Municipalities. National Tax Journal 51: 89-101.

Karch, A. (2001): Program Externalities, Federal Interventions and Policy Innovation in the American States. Paper presented at the Annual meeting of the APSA, San Francisco, September 2001. Mimeo, Harvard University.

Kinder, D.R. and Palfrey, T.R. (1992): Experimental Foundations of Political Science. Ann Arbor: University of Michigan Press. 
Kollman, K., Page, S.E. and Miller, J.H. (1997): Political Institutions and Sorting in a Tiebout Model. American Economic Review 87(5): 977-92.

Kollman, K., Page, S.E. and Miller, J.H. (2000): Decentralization and the Search for Policy Solutions. Journal of Law, Economics, and Organization 16(1): 102-28.

Kotsogiannis, C. and Schwager, R. (2001): Political Uncertainty and Policy Innovation. Discussion paper 01/11, Department of Economics, University of Exeter.

Ladd, H.F. (1992): Mimicking Local Tax Burdens among Neighboring Counties. Public Finance Quarterly 20: 450-67.

Lupia, A. and McCubbins, M.D. (1998): The Democratic Dilemma. Can Citizens Learn what they Need to Know? Cambridge: Cambridge University Press.

McCaffery, E.J. (2000): Cognitive Theory and Tax. In: C.R. Sunstein: (ed.), Behavioral Law and Economics. Cambridge: Cambridge University Press: 398-421.

McDermott, R. (2002): Experimental Methods in Political Science. Annual Review of Political Science 5: 31-61.

Mooney, C.Z. (2001): Modeling Regional Effects on State Policy Diffusion. Political Research Quarterly 54(1): 103-24.

Myers, D.J. (2001): Modeling Social Diffusion Processes using Event History Analysis: Some Conceptual Issues, Practical Considerations, and Empirical Patterns. Working paper Notre Dame University.

Plott, C.R. (1983): Externalities and Corrective Policies in Experimental Markets. Economic Journal 93(March): 106-27.

Rogers, E.M. (1995): Diffusion of Innovations, $4^{\text {th }}$ ed. New York: The Free Press.

Savage, R.L. (1985): Diffusion Research Traditions and the Spread of Policy Innovations in a Federal System. Publius 15(4): 1-27.

Smith, J.D. (2001): Horizontal and Vertical Federalism: The Diffusion of Legislative Policy Innovations in the American States. Working paper University of North Texas.

Smith, V.L., Williams, A.W., Bratton, W.K. and Vannoni, M.G. (1982): Competitive Market Institutions: Double Auction versus Sealed Bid-Offer Auctions. American Economic Review 72(3): 58-77.

Strumpf, K.S. (2002): Does Government Decentralization Increase Policy Innovation? Journal of Public Economic Theory 4(1): 207-41.

Walker, J. (1969): The Diffusion of Innovations among American States. American Political Science Review 63: 880-89.

Welch, S. and Thompson, K. (1980): The Impact of Federal Incentives on State Policy Innovation. American Journal of Political Science 24(4): 715-29. 


\section{Appendix A: Instructions on the auction}

This appendix provides a translation of experimental instructions from German.

\section{General Instructions for Participants}

You are now participating in an economics experiment funded by the research funds of the Austrian National Bank. The purpose of this experiment is to analyze decision behavior. You will be paid $€ 5$ for showing up on time. If you carefully read the instructions and follow the rules you can earn additional money. The $€ 5$ and all other money earned during the experiment will be paid to you in cash immediately after the experiment. In the experiment you earn points. These points will be exchanged for Euro according to the following exchange rate: 10 Points $=€ 0.1$. You are not allowed to speak to other participants during the experiment. If you have a question, please ask us. We will gladly answer your questions individually. It is very important that you follow this rule.

Here is a short description of the experiment; detailed instructions are provided below. You are now participating in a market experiment. In this market there are buyers and sellers who trade units of some commodity. You earn money by trading. How much you earn depends on your decisions and the decisions of others. The experiment has two practice periods followed by a number of trading periods. In the practice periods you do not earn money but you should take these periods seriously since you will gain valuable experience for the trading periods that are paid.

\section{Detailed Instructions for Buyers}

In this experiment each participant is a buyer. You can buy units from automated sellers. These automated sellers will sell to you according to the rules of the market. In your market there are 5 buyers who can buy units from sellers in each of the trading periods.

What participants can do: As a buyer you will be assigned a value for a unit of the good. You can submit 'bids' to buy from the sellers during a trading period. A bid is the maximum price you are willing to pay for a unit. Each buyer is assigned a certain number of 'unit values'. You will submit bids only for that single unit.

The sellers are assigned costs for units. In each trading period sellers submit 'offers' to sell units to the buyers. An offer is the minimum price at which a seller is willing to sell a unit.

How the market works: At the end of each trading period the 'market quantity' and the 'market price' are determined. The market quantity is the total number of units traded in the market. The market price is a uniform price at which all units are traded in the market.

How the market quantity is determined: First, the bids you and other buyers in your market have submitted are collected and ranked from high to low. The highest bid is ranked above the 2nd highest bid. The 2nd highest bid is ranked above the 3rd highest bid, and so on. If two or more bids are the same, ranks will be randomly assigned by the computer. Second, all the sellers' offers in your market are collected and ranked from low to high. The lowest offer is ranked above the 2 nd lowest offer. The 2 nd lowest offer is ranked above the 3rd lowest offer, and so on. 
A first unit is traded if the 1st ranked bid is higher or equal to the 1st ranked offer. A second unit is traded if the 2 nd ranked bid is higher or equal to the 2 nd ranked offer. This process continues until bids are smaller than offers at a given rank. The total number of units that have been traded when the process stops is the 'market quantity'.

Example: Assume we collect four bids and four offers in a market period. The highest bid is 145 , the 2 nd highest bid is 130 , the 3 rd highest bid is 110 , and the 4 th highest bid is 90 . The lowest offer is 60 , the 2 nd lowest offer is 80 , the 3rd lowest offer is 95 , and the 4th lowest offer is 105. A first unit is traded since the highest bid (145) is greater than the lowest offer (60). A second unit is traded since the 2nd highest bid (130) is greater than the 2nd lowest offer (80). A third unit is traded since the 3rd highest bid (110) is greater than the 3rd lowest offer (95). The process stops after the third trade since the 4th highest bid (90) falls below the 4th lowest offer (105). Hence, the market quantity is equal to 3 units.

How the market price is determined: The market price is set at the bid for the last unit that has been traded before the process stopped. All units are traded at that market price. In the example above three units have been traded. The bid for the last unit that has been traded is 110. Hence the market price is set equal to 110 . It is important to note that all units in the market are traded at this same price of 110 .

When do you buy a unit? You buy your unit if your bid is above the market price. You do not buy the unit if your bid is below the market price. You may or may not buy if your bid is exactly at the market price (your bid may randomly happen to be ranked below another bid at the market price so that the offer at that rank exceeds your bid). If you do not submit a bid on a unit (this is equivalent to submit a bid of 0 ), you never buy that unit.

The number of units the sellers sell is determined by the number of offers at or below the market price.

How your profit is computed: Your profit as a buyer is computed as follows: Profit = unit value minus market price. Note that if you buy your unit you will pay less than your bid unless your bid is at the market price. In our example, suppose that you submitted the bid of 130 for a unit you value at 150 . This bid is above the market price of 110 . Since you buy this unit at a market price of 110 your profit will be $150-110=40$.

The profit of a seller is computed as follows: Profit = market price minus unit cost.

Important: The information on values and costs of a unit a private. That means that each buyer (seller) only knows her own value (costs) but not those of the other buyers (sellers).

How the automated sellers make their offers: At any time the sellers follow two rules in offering:

1. 'Submit an offer for each unit assigned.' This means that the sellers will submit an offer for each unit they have been assigned a unit cost.

2. 'Submit offers equal to the cost of a unit.' This means that an offer to sell a unit is always exactly equal to the unit cost. Since the sellers do not sell the units that they have offered above the market price, a seller never trades at a loss.

How is the trade presented on the computer screen? In each trading period a Decision Screen appears (Figure 1). At the end of each period an Outcome Screen appears (Figure 2). After 15 trading periods a History of Results appears (Figure 3). 
Subjects' original instructions contained figures showing what the computer screens look like during the experiment.

All the numbers in the figures in the instructions serve illustrative purposes only. Actual numbers may be different.

In the uppermost area of the Decision Screen on the left side you see the number of the current trading period (here: 2) and the total amount of trading periods (here: 15). Each trading period ends after a predefined time limit. The remaining time within a period is seen in the uppermost area to the right (here: 19 Seconds). In the beginning of the experiment, the available time for trading is generous and will be continuously shortened afterwards.

In the field on the top left you find your value. In this example the buyer has a value of 150 . Please, note once more: Every buyer knows his own value only.

The input field on the bottom left serves to enter your bid. To enter a bid you click with the mouse on the field labeled 'Your Bid' and type in a number. To submit that bid you have to click on the 'Submit' button.

In the column to the right you see your current bid. In our example this buyer has already submitted a bid of 130 (see "current bid"). During the trading period the buyer can change his or her current bid on a unit. This buyer has already typed in a number to the input field of the 1st unit. Pressing 'Submit' will let appear a message box asking 'Do you want to replace your current bid?' Confirming by clicking 'Yes' would change the current bid from 130 to 140.

Rule for bidding: An important rule for trading is to "trade at no loss". Therefore, you may not submit a bid above your unit value. In our example of Figure 1, this buyer's bid for the first unit must not be above 150. If you violate this rules, a message box appears. You make this message disappear by pressing the 'OK' button.

The Outcome Screen (Figure 2) appears at the end of the current trading period. The uppermost area of this screen appears same as the Decision Screen. In the lines below you find your value, your bid, the market price, and your market profit from buying your unit. Your market profit is the difference between your value and the market price (here: 40)

In the next line the total number of units traded in the market (Market Quantity) is shown. The lines below this one (Additional costs, Additional costs per person, Net-payoff) is not of interest at this place and will be explained further down.

The line "Your initial endowment" shows a constant income you earn irrespective of market outcomes (here: 50). Just as your value, your initial endowment is private information and may not be communicated with other participants.

The last line finally gives Your Period Profit as the sum of your market profit and your initial endowment.

The History of Results (Figure 3) shows the results of a trading phase. A phase consists of 15 trading periods. In the field on the left top there is a list of he abbreviations used. In the table below for each period you find the market price (Price), the market quantity (Q), your market profit (Profit), your initial endowment (E), and your period profit (Iper). The example of Figures 1 and 2 is continued in Figure 3. The column 'Additional cost from trading per person" is not of interest at this place and will be explained further down. 
The following text in brackets [ ] was used in T(full) only. [In the area below the table you find information concerning the other groups in the experiment (each group builds a market with five buyers). There the average income AvY in each market is given. On the right you see which is your group.]

At the right bottom of the screen Your Total Profit on all paid periods within this phase is shown. Your Total Profit is computed as the sum of your period profits. The periods labelled as 'Trial' are not considered in the computation of the total profit.

"Additional Costs" from Trading

Each unit traded at the market causes costs for every buyer. These costs are called "additional costs". Per unit the additional costs are 90 points. At the end of each trading period the additional costs are divided equally among all five buyers in your market. Note that you will bear a share of the additional costs even if you do not buy your unit yourself.

Example: Suppose market quantity is 3 units. Additional costs are $90 * 3=270$. These costs are equally divided between the five buyers in your market. In this example each buyers' share from additional costs is $270 / 5=54$. Consequently, each buyer's period profit reduces by 54 points.

How additional costs are displayed on the screens: The Outcome screen in the lines below the "Market quantity" shows additional costs from trading ("Additional costs") and the share per buyer ("Additional costs per person"), Net-payoff denotes your payoff from market activity reduced by your share from additional costs. (i.e., Your Market profit minus Additional costs per person).

The History of Results of a trading phase also contains a column that shows your share of additional cost for each trading period.

If you now have questions, please, raise your hand and wait until an experimenter will come by to answer your question individually. 


\section{Appendix B: Instructions on the Proposal}

You and 4 (four) other buyers will now vote on a tax to be imposed on trading the good in the market. If the majority, i.e., at least 3 buyers approve of the tax it is accepted. Otherwise it is rejected. All participants will be immediately informed of the outcome of the voting. Voting is anonymous.

If the tax is rejected we proceed for another 15 trading periods exactly as in the previous 15 periods. If the tax is accepted the following changes are implemented for the next 15 trading periods: Sellers in the market pay a tax of 90 points on each unit they sell.

If the tax is accepted all the rules pointed out in the instructions remain valid. Most importantly, note that sellers can only make selling offers that do not result in a loss.

Example: Suppose a seller's cost for a unit are 30. According to the rules for trading, this seller has to make an offer equal to 30 . If the tax is accepted, the seller now has to make an offer of 120 because of the tax.

\section{Appendix C: History of Results Screen in T(full)}

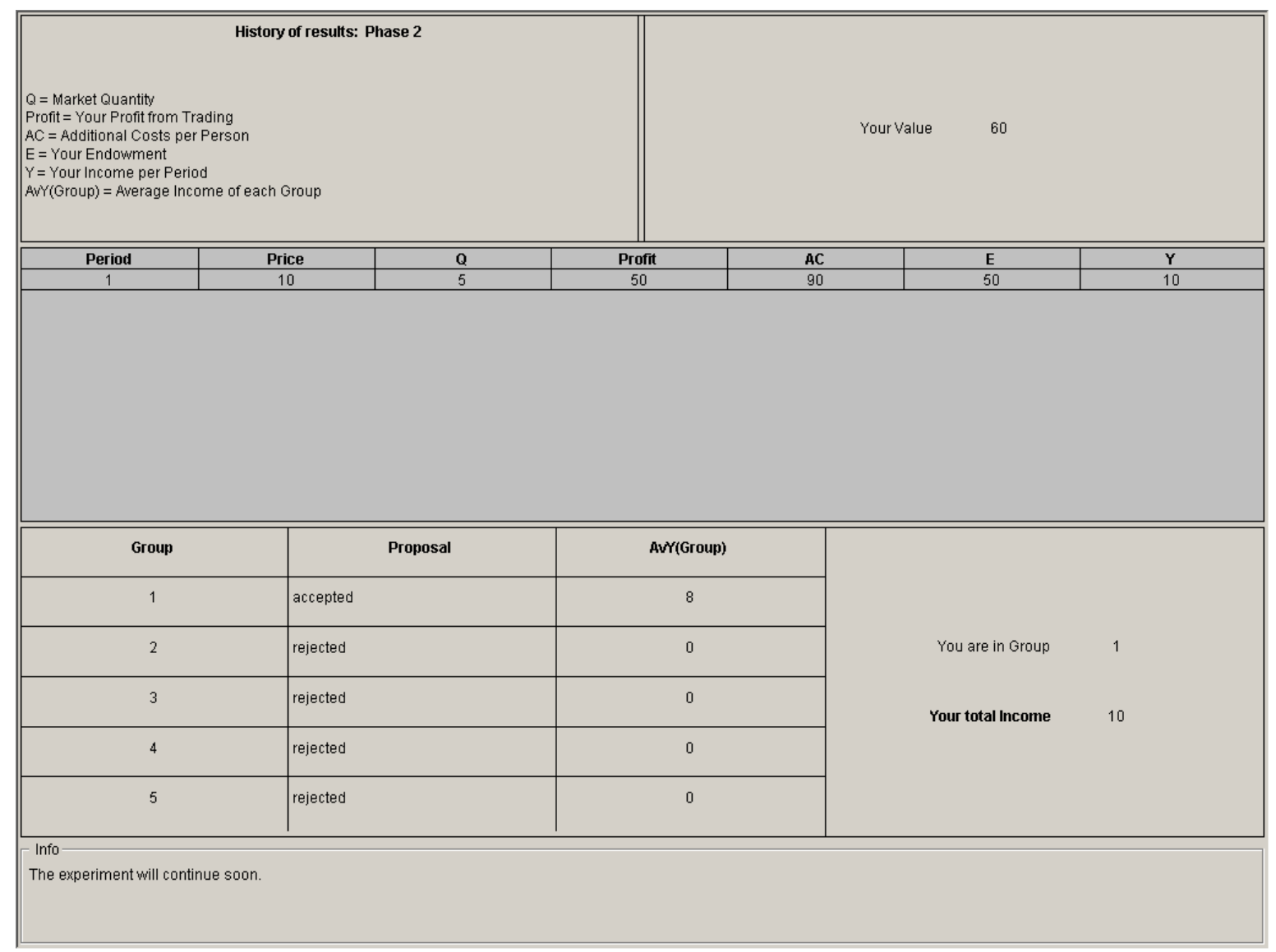

